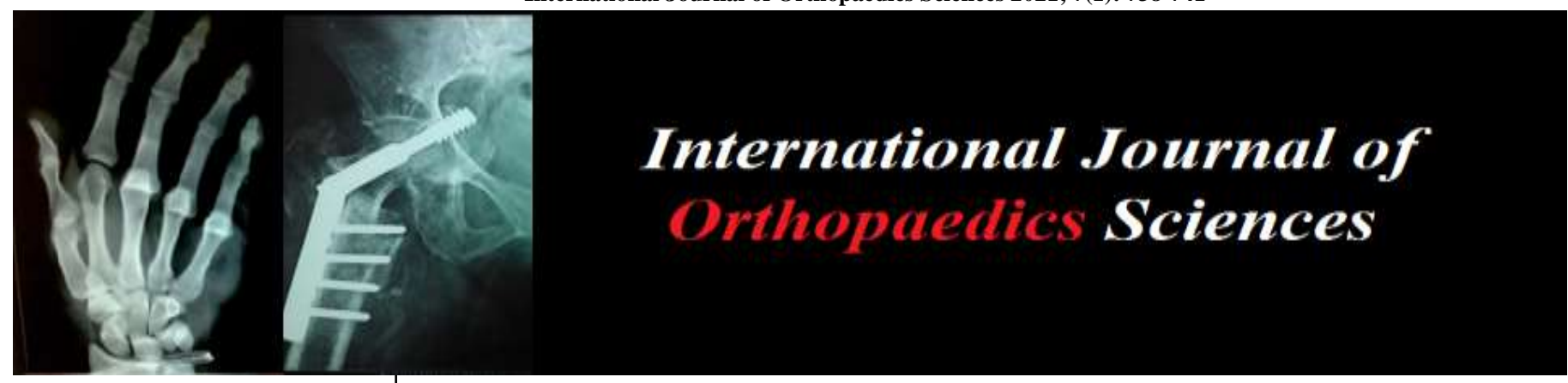

E-ISSN: 2395-1958

P-ISSN: 2706-6630

IJOS 2021; 7(1): 738-741

(C) 2021 IJOS

www.orthopaper.com

Received: 11-10-2020

Accepted: 02-12-2020

Dr. Sandeep Sriram

The Hand Surgery Clinics,

Pune Sancheti Institute for

Orthopaedics and Rehabilitation

(SIOR), Pune, Maharashtra,

India

Dr. Nishant Jajee

Gulburga institute of medical

sciences, Gulbarga, Karnataka

India

Dr. Prashant Dhanraj

Department of Orthopaedics,

KAMSRC, L.B. Nagar

Hyderabad, Telangana, India

Dr. Sunkoj Krishna Sai

Department of Orthopaedics,

KAMSRC, LB Nagar,

Hyderabad, Telangana, India

Corresponding Author:

Dr. Sandeep Sriram

The Hand Surgery Clinics,

Pune Sancheti Institute for

Orthopaedics and Rehabilitation

(SIOR), Pune, Maharashtra,

India

\section{Functional outcome of tibial fractures in children treated by supracutaneous locking plates}

\author{
Dr. Sandeep Sriram, Dr. Nishant Jajee, Dr. Prashant Dhanraj and Dr. \\ Sunkoj Krishna Sai
}

DOI: https://doi.org/10.22271/ortho.2021.v7.i11.2563

\section{Abstract}

Background: Tibial shaft fractures are third most common type of long bone fractures in children after femur and forearm.

Aim: The purpose of the study is to evaluate the functional and radio logical outcome results of Closed reduction or open reduction of tibial fractures and fixation using locking plate as supra cutaneous external fixator in children.

Methods: In this observational study 32 children with tibial fractures having soft tissue injury underwent external fixation with locking plates. There were 22 male and 10 female children with mean age of 10.59years (range 6 to 15 years) who sustained fracture in RTA. $84.4 \%$ cases had closed fractures, and $15.6 \%$ cases had open fractures. Out of the cases with open fractures, $60 \%$ had grade 1 injury, and $20 \%$ each had grade 2 and grade $3 \mathrm{~b}$ injury respectively.

Results: 7, 9, 11, 13 Holed LCP were used in $34.4 \%, 25 \%, 25 \%$ and $15.6 \%$ patients respectively. Screw tract infections were observed in two patients who had serious discharge and was relieved with oral antibiotics. No deep infections were reported. All the fractures united by the end of 24 weeks after bone grafting. In all most all the patients skin condition was found to be good in follow up.

Conclusion: The present study though in small number (32) shows that use of LCP plate as supra cutaneous external fixator is an effective method in terms of stability of fixation, utilisation as permanent fixation method and less complication rate.

Keywords: Tibial fractures, locking plates, fibula fracture

\section{Introduction}

Tibial shaft fractures are third most common type of long bone fracturesin children after femur and forearm ${ }^{[1]}$. This tibial fractures accounts for $15 \%$ of total pediatric fractures and the majority of them results from fall during recreational activities and RTA that can be treated conservatively by cast immobilization with excellent outcomes, including four to six weeks of long leg cast followed by a short leg cast or a removable fracture boot ${ }^{[2]}$. However, operative interventions are mandatory when the mechanism of injury is secondary to a direct impact that involves a skin injury with or without exposure of the fracture site, a compartment syndrome and an unstable and displaced fracture ${ }^{[3,4]}$.

Two main surgical techniques have been reported to be effective in treating tibial shaft fractures in skeletally immature children: internal fixation (elastic nails and screws) and external fixation (standard external fixators and supra cutaneous locking plates) ${ }^{[3-6]}$. Internal fixation with a screw is a suitable option, but is not stable enough to be used alone and requires supplemental long leg cast application. Elastic stable intramedullary nailing has been commonly used since it provides stability, flexible mobility and is usually performed by closed reduction ${ }^{[4-6]}$. No rotational stability is offered by intramedullary elastic /TENS nails [6]. Several major complications such as compartment syndrome, malunion, nonunion, leg length shortening and nail migration have been allocated to the use of intramedullary nailing compared with external fixation ${ }^{[7,8]}$. Standard external fixators are relatively inexpensive and easy to apply. However, frames are often bulky and cumbersome. Patients typically encounter problems with clothing and in day to day activities. They may also cause disturbance in gait while trying to clear from the opposite limb during the swing phase ${ }^{[9,10]}$. 
Recently, the use of locking plate as an external fixation without joint spanning has been used as part of staged reconstruction in the management of open tibial fractures [1113]. The locking plate used as a definitive external fixator is attractive because it not only minimizes trauma to the soft tissues, but also overcomes the short comings of standard external fixators ${ }^{[14-16]}$. We report in this study, the outcome of anatomically contoured locking plates as an external fixator device in the fractures of tibia ${ }^{[13-15]}$.

There are two broad categories of locking plates: fixed-angle locking plates and variable - angle locking plates. $\mathrm{N}$ the latter, the screw can be locked with a certain clearance within a cone with an angle on the order of 1 - 15. The mechanism locking the screw in the plate also comes in two types: in the first the screw head is locked in its chamber by a threaded lock nut. In the second, the screw head is itself threaded and screws into the plate or into an adapted lip.

The LCP Fixator impacts a lower profile than a traditional fixator and can be concealed under clothing, making it more acceptable to patients. Hardware removal can be performed in an out patient setting under local anesthesia. The LCP fixator imparts a less conspicuous radio graphic silhouette compared with traditional fixators.

\section{Materials and methods}

This is a prospective observational study involving 32 subjects. Between June 2018 and May 2019, 32 children with tibial fractures having soft tissue injury underwent external fixation with locking plates at Kamineni Academy of medical sciences and Research institute. There were 22 male and 10 female children with mean age of 10.5 years (range 6 to 15 years). All 32 patients sustained fracture in Road Traffic Accidents. There were 5 open fractures. Injury grading was done after wound debridement. Grades include 2 Gustilo type II-3 patients and Gustilo type I-2 patients. 27 patients were having closed injuries. 7 children with isolated tibia fractures, 15 patients along with fibula fractures, 3 children with associated upper limb fractures, 1 child with ipsilateral foot metatarsal fracture and 2 children with ipsilateral femur fractures. The mean time between injury and operation was 1 day in closed fractures. For open fractures, external plating was performed after debridement during the emergency operation.

Patients were evaluated based on Clinical examination of injury, grade of open injury, grade of communition, $\mathrm{X}$ ray AP and lateral views and fracture pattern. Fibula fracture was observed in $71.9 \%$ patients. Soft tissue injury was observed in

$15.6 \%$ patients. Fracture shaft of Humerus was observed in $6.3 \%$ patients. Fracture shaft of Femur was observed in $3.1 \%$ patients. Supracondylar fracture of Femur was observed in $3.1 \%$ patients. Fracture both bone forearm was observed in $3.1 \%$ patients. Metatarsal fracture was observed in $3.1 \%$ patients. No additional injury was observed in $21.9 \%$ patients. Toe touch walking and partial weight bearing were allowed as tolerated by the patient from the first postoperative day. Active knee and ankle ROM exercises were included in rehabilitation.

Inclusion criteria: Skeletally immature children (5-15yrs) with a displaced and unstable fracture with open Gustilo I, II and IIIA, IIIB tibial fracture or closed fractures with soft tissue injury.

Exclusion criteria: All Tibial fractures that can be treated conservatively by cast immobilization, skeletal congenital diseases and systemic or metabolic diseases were excluded, pathological fractures, any co-existing local conditions in the form of neoplastic disease, ill reduced fractures, physeal epiphyseal injuries of tibia, intra articular fractures, fractures that need dynamization, bone transport procedures and patients with polytrauma where other organ systems are involved.

\section{Results}

Table 1: Distribution of the Participants in Terms of Type of Fracture

\begin{tabular}{|c|c|c|}
\hline Type of Fracture & Frequency & Percentage \\
\hline Closed Fracture & 27 & $84.4 \%$ \\
\hline Open Fracture & 5 & $15.6 \%$ \\
\hline Grade of Open Fracture & Frequency & Percentage (n = 5) \\
\hline Grade 1 & 3 & $60.0 \%$ \\
\hline Grade 2 & 1 & $20.0 \%$ \\
\hline Grade 3b & 1 & $20.0 \%$ \\
\hline
\end{tabular}

Table 2: Distribution of the Participants in Terms of Associated Injury

\begin{tabular}{|c|c|c|}
\hline Associated Injury & Frequency & Percentage \\
\hline Fibula Fracture & 23 & $71.9 \%$ \\
\hline Soft Tissue Injury & 5 & $15.6 \%$ \\
\hline Fracture Shaft of Humerus & 2 & $6.3 \%$ \\
\hline Fracture Shaft of Femur & 1 & $3.1 \%$ \\
\hline Supracondylar Fracture of Femur & 1 & $3.1 \%$ \\
\hline Fracture Both Bone Forearm & 1 & $3.1 \%$ \\
\hline Metatarsal Fracture & 1 & $3.1 \%$ \\
\hline None & 7 & $21.9 \%$ \\
\hline
\end{tabular}

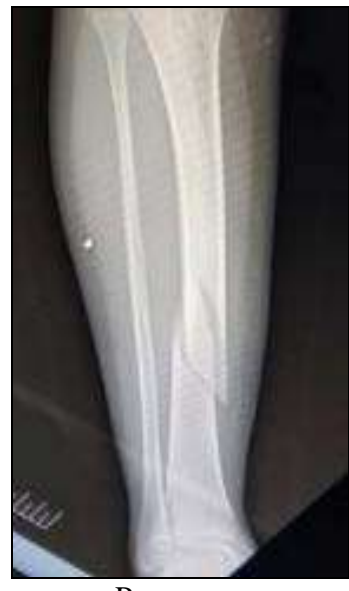

Pre-op

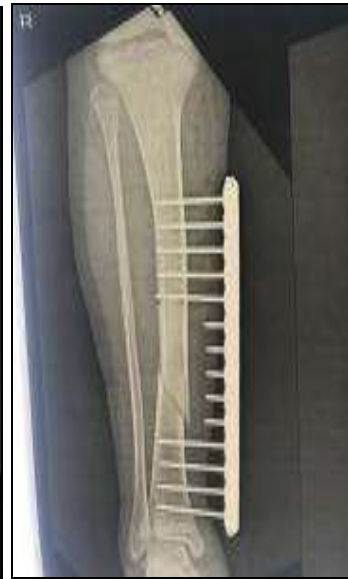

Immediate post-op

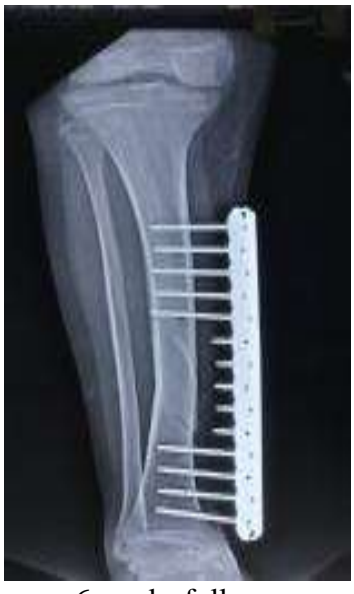

6 weeks followup

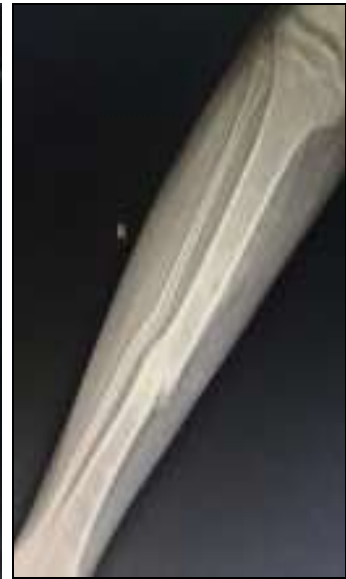

After implant removal

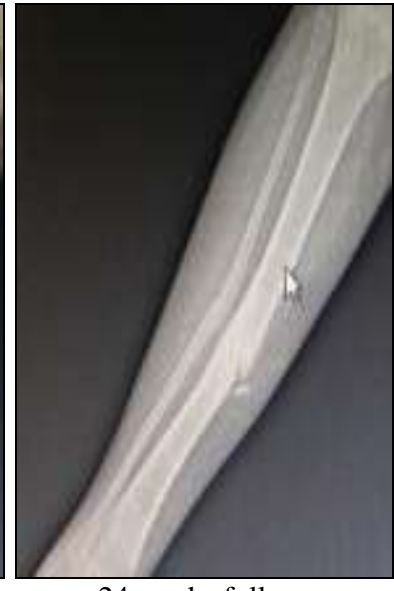

24 weeks followup

Fig 1: X Rays 
Table 3: Distribution of the Participants in Terms of Complication

\begin{tabular}{|c|c|c|}
\hline Complication & Frequency & Percentage \\
\hline Screw Site Infection & 2 & $6.3 \%$ \\
\hline Delayed Union & 2 & $6.3 \%$ \\
\hline Gap Non-Union & 1 & $3.1 \%$ \\
\hline
\end{tabular}

Table 4: Change in RUST Score over Time

\begin{tabular}{|c|c|c|c|c|}
\hline \multirow{2}{*}{ Time Point } & \multicolumn{2}{|c|}{ RUST score } & \multicolumn{2}{c|}{$\begin{array}{c}\text { Repeated Measures } \\
\text { ANOVA }\end{array}$} \\
\cline { 2 - 3 } & Mean & SD & F & P Value \\
\hline 6-Weeks Follow-Up & 7.53 & 1.05 & & \\
\hline 12-Weeks Follow-Up & 11.03 & 1.31 & \multirow{2}{*}{325.830} & $<0.001$ \\
\hline 24-Weeks Follow-Up & 11.78 & 1.07 & & \\
\hline
\end{tabular}

Tibial fracture in children with or without articular extension is one of the difficult fractures to manage. Locking plate is an friction-free, independent self stable construction which provides both angular and axial stability and minimizes risk of secondary loss of reduction through a threaded interface between the screws heads and plate body. 32 patients were included in the study with mean age of 10.59 (6-15 years) in period from during 2018 June to 2019 may and all the patients had maximum follow up of 24 weeks except. Other studies were $n 31,33,37,38=42,19,38,12$ with average ages of 13 , 11,14 . In this study male and female patient were $22 \mathrm{n} 10$ respectively. Among the 32 children, mean hospital stay was 3.28 days ranging from 1-8 days. Plates were kept in situ till radio logical signs were appeared, full weight bearing was allowed. Plates were kept in-situ for 6 weeks after radio logical signs of union of 4 cortices. "Controlled destiffering" or dynamization by removing screws closest to the fracture site is possible, allowing some measure of control to the load sharing process. Implant was done as a simple OPD procedure. No screw tract infections were observed except in 2 patients who had serious discharge and is relieved with oral antibiotics. No deep infections were reported. No implant failure was noted among the subjects. No patients had limb length discrepancy. One screw was found to be loose during visits was removed. The reason for loosening is assumed to be improper locking of screw head. In patients having closed grade II fractures, radiological union occurred by 12 weeks. All fractures are united except one grade III B injury in which the distal shaft extension of the fracture appears to be non union by the end of 24 weeks. Bone grafting was done at the non union site and at the follow up till the end of study shows good callus formation. Reason for non union site is attributed to the severity of injury. Patients were advised to walk with support for 2 weeks after implant removal in order to avoid secondary fractures at the screw hole sites. Skin condition was good in all patients at the follow up. The consistent good outcome using this "supra cutaneous technique", support our opinion of using locking compression plate as external fixator in tibial fractures which are very well tolerated by patients and address the challenging problems.

\section{None of the participants had any limb length discrepancy}

The mean RUST score at 6-Weeks Follow-Up was $7.53 \pm$ $1.05,12-W e e k s$ Follow-Up was $11.03 \pm 1.31$, and at 24Weeks Follow-Upwas $11.78 \pm 1.07$. There was a significant increase in RUST score from 6-Weeks Follow-Up to 12Weeks Follow-Up and 24-Weeks Follow-Up time points ( $\mathrm{F}=$ 325.830, $p<0.001)$.

The mean maximum knee flexion angle at 6-weeks follow-up was $117.19( \pm 9.91)$ degrees, at 12-weeks follow-up was $123.44( \pm 9.02)$ degrees and at 24-weeks follow-up was 140
$( \pm 0)$ degrees (full ROM). The mean ankle plantar flexion angle at 6-weeks follow-up was $21.63( \pm 2.47)$ degreesm 12weeks follow-up was $20( \pm 0)$ degrees and at 24-weeks followup was $30( \pm 0)$ degrees. The ankle Dorsi-flexion angle at 6weeks follow-up was neutral, at 12-weeks follow-up was 10 $( \pm 0)$ degrees and 24-weeks follow-up was $18.28( \pm 2.73)$ degrees.

Screw Site Infection was present in $6.3 \%$ of the patients. Delayed Union was present in $6.3 \%$ of the patients. Gap NonUnion was present in $3.1 \%$ of the patients. Wound debridement was required in $6.3 \%$ of the patients. Bone grafting was required in $3.1 \%$ of the patients.

\section{Discussion}

Tibial fractures in children which are either open or closed fractures, with or without communition is one of the difficult fractures to manage. The prevalence of tibia non-unions increases with the severity of open fractures. The endosteal and periosteal blood supply is often extensively destroyed when the open fractures occur, which are considered as the most important in the healing of tibia fractures ${ }^{[9]}$.

Regular External fixators as a definitive method of treatment for tibial fracture are recommended only for open fractures with severe soft tissue injury $[13,15,16]$.

Few studies suggest the use of locking plates as external fixators ${ }^{[17,18]}$. Using Locking compression plate preserves the vascularity of tibia and promotes union. Nonunion due to infection in compound fractures of tibia is a commonly encountered scenario which can be avoided by external stabilization devices ${ }^{[19]}$.

Primary closure was achieved for all open injuries except one patient with open Grade III B injury were closure was done after a week, which local flap needed closure with skin grafting. 1 patient with grade 3 b injury $(3.1 \%)$ had butterfly fragment bone loss.

A non-union rate of $3.1 \%$ is observed in this study and nonunion rate $2.9-9.3 \%$ had been noted by other authors [20, 21] (out of 39 patients,27 patients) in this technique of fixation compared to $21 \%$ as in conventional external fixation 21,22 (44,57 patients).

29 patients were allowed to guarded weight bearing immediately after surgery with and knee/ankle range of motion exercises were initiated in $90.6 \%$ patients. Delayed weight bearing was initiated in $9.4 \%$ patients.

The mean time to implant removal of the participants was $6.34(+/-0.70$ weeks) time of implant removal ranged from 5 to 9 weeks. Full weight bearing was started in 28 patients (87.5\%) Immediately after implant removal. Casting for 2 weeks and delayed weight bearing were required in $9.4 \%$ patients ${ }^{[6]}$. Non weight bearing was required in $3.1 \%$ of patients. None of the patients had any limb length discrepancy.

The mean ankle plantar flexion angle at 6-weeks follow-up was $21.63( \pm 2.47)$ degrees. The mean ankle plantar flexion angle at 12-weeks follow-up was $20( \pm 0)$ degrees. The mean ankle plantar flexion angle at 24-weeks follow-up was $30( \pm 0)$ degrees.

Screw tract infections were observed in two patients who had serious discharge and is relieved with oral antibiotics. No deep infections were reported. No implant failure were noted in all the subjects.

In all patients having closed and open fractures radiological union occurred by 12 weeks (RUST Score 11.03).

All the fractures united except one Grade 3 B injury which was found to have gap Non- Union and union occurred by the 
end of 24 weeks after bone grafting. Reason for Non union is attributed to severity of injury with butterfly fragment bone loss of $1 \mathrm{~cm}$.

\section{Conclusion}

Tibia fractures or without intra articular extension, with or without significant soft tissue injury is one of difficult fractures to manage with all currently available treatment options. Tibial fractures treated by using locking plates as fixators utilized as permanent fixation method, Ease of application and implant removal, reduced hospital stay, union time and complications rate and less radio graphic silhouette and low profile. Implant compliance is good there is less chance of striking contralateral lower limb during walking and the low profile plate can be concealed under stockings and it is aesthetically acceptable. It is believed that the supra cutaneous locking plate technique is an effective procedure for treatment of tibial fractures in patients who need a long period of external fixation. Ankle sparing stable fixation with good reduction is achieved immediately. Soft tissue reconstruction where ever necessary, led to union of all fractures with good function.

\section{References}

1. Patel NK, Horstman J, Kuester V, Sambandam S, Mounasamy V. Pediatric tibial shaft fractures. Indian $\mathbf{J}$ Orthop 2018;52:522-8.

2. Shannak AO. Tibial fractures in children: Followup study. J Pediatr Orthop 1988;8:306-10.

3. Mann DC, Rajmaira S. Distribution of physeal and nonphyseal fractures in 2,650 long-bone fractures in children aged 0-16 years. J Pediatr Orthop. 1990;10:7136

4. Canavese F, Botnari A, Andreacchio A, Marengo L, Samba A, Dimeglio A et al. Displaced tibial shaft fractures with intact fibula in children: Nonoperative management versus operative treatment with elastic stable intramedullary nailing. J Pediatr Orthop 2016;36:667-72.

5. Gougoulias N, Khanna A, Maffulli N. Open tibial fractures in the paediatric population: A systematic review of the literature. Br Med Bull 2009;91:75-85.

6. Griffet J, Leroux J, Boudjouraf N, Abou-Daher A, El Hayek T. Elastic stable intramedullary nailing of tibial shaft fractures in children. J Child Orthop 2011;5:297304.

7. Vallamshetla VR, De Silva U, Bache CE, Gibbons PJ. Flexible intramedullary nails for unstable fractures of the tibia in children. An eight-year experience. J Bone Joint Surg Br 2006;88:536-40

8. Herman MJ, Martinek MA, Abzug JM. Complications of tibial eminence and diaphyseal fractures in children: Prevention and treatment. J Am Acad Orthop Surg 2014;22:730-41.

9. Economedes DM, Abzug JM, Paryavi E, Herman MJ. Outcomes using titanium elastic nails for open and closed pediatric tibia fractures. Orthopedics 2014;37:e619-24.

10. Hope PG, Cole WG. Open fractures of the tibia in children and outcomes external fixators. J Bone Joint Surg Br 1992;74:546-53.

11. Tolo VT. External skeletal fixation in children's fractures. J Pediatr Orthop 1983;3:435-442.

12. Yusof NM, Oh CW, Oh JK, Kim JW, Min WK, Park IH, et al. Percutaneous plating in paediatric tibial fractures. Injury 2009;40:1286-91
13. Zhao W. Locking plate percutaneous external fixation for the treatment of pediatric tibial fractures. Zhongguo Gushang 2014;27:597-600.

14. Zhang JW. Distal tibial fracture: An ideal indication for external fixation using locking plate. Chinese Journal of Traumatology 2016;19:104-108.

15. Gougoulias NE, Khanna A, Maffulin N. Open tibial fractures. Are children small adults. Hippokratia 2009; 13:147-53.

16. Kubiak EN, Egol KA, Scher D et al. Operative treatment of tibial fractures in children: are elastic stable intramedullary nails an improvement over external fixation J Bone Joint Surg [Am] 2005;87-A:1761-1768

17. AO manual of fracture management, internal and external fixators, concept and cases using LCP ,LISS Stuttgart, Illizarov and external fixators, New York: Thieme 2006.

18. Russell T. A An historical perspective of the development of plate and screw fixation and minimally invasive fracture surgery with a unified biological approach Tech Ortho 2007;22:186-190.

19. Sommer C. Locking compression plate - LCP - A new AO principle Injury 2003;34(2):1-76

20. Ziran BH, Smith WR, Anglen JO, Tornetta P. III: External fixation: How to make it work. J Bone Joint Surg Am 2007;89:1619-32.

21. Ma CH, Wu CH, Tu YK, Lin TS. Metaphyseal locking plate as a definitive external fixator for treating open tibial fractures-clinical outcome and a finite element study. Injury 2013;44(8):1097-101.

22. Ramotowski W, Granowski R. Zespol,an original method of stable osteosynthesis Clin Orthop Relat Res 1991;272:67-75. 